\title{
Endogenous Ethylene and Color Development in the Skin of 'Pink Lady' Apple
}

\author{
Suparna K. Whale ${ }^{1}$ and Zora Singh ${ }^{2,3}$ \\ Horticulture, Muresk Institute, Division of Resources and Environment, Curtin University of \\ Technology, GPO Box U1987, Perth 6845, Western Australia
}

AdDitional INDEX words. Anthocyanin, quercetin glycosides, flavanols, flavonoids, fruit development, Malus $\times$ domestica

\begin{abstract}
To elucidate the temporal relationship between endogenous ethylene and color development, changes in ethylene concentration, fruit color, pigments, and flavonoids were monitored at different intervals during the development and ripening of 'Pink Lady' apple (Malus $\times$ domestica Borkh.), commencing from 60 days after full bloom (DAFB) in 2002 to 2003, and 7 DAFB in the 2003 to 2004 season. Concentrations of chlorogenic acid, phloridzin, catechin, epicatechin, and quercetin glycosides were significantly higher $(P \leq 0.05)$ during the early stages $(7-60$ DAFB) compared with the later stages $(\geq 60$ DAFB) of fruit growth. During fruit development, concentrations of phloridzin, catechin, epicatechin, and quercetin glycosides decreased to low and stable levels. However, the concentration of anthocyanin (cyanidin 3-galactoside) increased during maturation and ripening ( $\geq 168$ DAFB), coinciding with a corresponding increase in percent red blush and endogenous ethylene concentration. Positive and significant correlations were found between ethylene and color development and between ethylene and total anthocyanin, but not the other flavonoid compounds. Ethylene therefore appears to be a key factor regulating anthocyanin biosynthesis and color development in 'Pink Lady' apple. However, the accumulation of other classes of flavonoids such as catechin, epicatechin, phloridzin, chlorogenic acid, and quercetin glycosides seems to be regulated independently of ethylene during fruit development and ripening.
\end{abstract}

Traditionally, apples are grown in temperate climates. The development of new cultivars such as Pink Lady, which require less than $400 \mathrm{~h}$ at less than $7^{\circ} \mathrm{C}$ (Mackay et al., 1994) to flower regularly, has made it possible to grow apples in the warmer parts of the world, including the Mediterranean regions, California, South Africa, and Australia. However, optimum fruit color development, particularly red blush at harvest, is still a major problem with 'Pink Lady' apples in these applegrowing areas. Poor and erratic color development often causes serious economic losses to the growers.

Apple skin color results from the blending of chlorophyll, carotenoid, and anthocyanin pigments (Lancaster, 1992), with anthocyanins being primarily responsible for the red color (Lancaster, 1992). Apple skin also contains high concentrations of flavonols (quercetin 3-glycosides), flavanols (catechin, epicatechin, gallocatechin), dihydrochalcones (phloridzin), and hydroxycinnamic acid (chlorogenic acid) (Awad and de Jager, 2000; Lancaster, 1992). These flavonoids, including anthocyanins, form a group of plant secondary metabolites that are believed to contribute to human health with their antioxidant, free radical scavenging, anticarcinogenic, and antiinflammatory properties (Rice-Evans et al., 1997). The phenolic composition of apples varies among cultivars (Napolitano et al., 2004), and the chemical composition and concentration

Received for publication 16 Dec. 2005. Accepted for publication 28 Sept. 2006. S.K. Whale gratefully acknowledges the financial support of an International Postgraduate Research Scholarship from Curtin University of Technology, Perth, Western Australia.

We are grateful to M.H. Behboudian (Massey University, New Zealand) and E. Swinny (Chemistry Center, Western Australia) for critically reviewing this manuscript. We thank A. Giumelli and Sons, Carmel, Western Australia, for providing us with the trees used for these experiments. We also thank Michael Boddy for his assistance with the high-performance liquid chromatography analysis and Ritu Gupta for her help with the statistical analysis.

${ }^{1} \mathrm{PhD}$ student.

${ }^{2}$ Associate Professor Horticulture.

${ }^{3}$ Corresponding author. E-mail: Z.Singh@curtin.edu.au. of flavonoids and phenolic compounds is influenced by genetic variations, geographical location, and changes during the growing season and growth period (Tsao et al., 2003). It is therefore important to determine the pigment and flavonoid profile of new apple cultivars.

The accumulation of anthocyanins is influenced by light, temperature, ethylene, and cultural practices (Lancaster, 1992; Saure, 1990). Endogenous ethylene is closely associated with red color development and anthocyanin accumulation in fruit skin (Blankenship and Unrath, 1988). The concentration of endogenous ethylene in ripe apples can vary between 25 and $2500 \mu \mathrm{L} \cdot \mathrm{L}^{-1}$ (Burg and Burg, 1962). Kondo et al. (1991) reported that accumulation of anthocyanin in the fruit skin paralleled the increase in internal ethylene concentration during the growth and maturation of 'Tsugaru', 'Senshu', and 'Fuji' apples. Ethylene is therefore considered to affect anthocyanin biosynthesis directly by some researchers, whereas others believe that accumulation of anthocyanin is an indirect response to advancing maturity (Saure, 1990). However, the influence of ethylene on the accumulation of other classes of flavonoids is yet to be investigated. Understanding the changes in endogenous ethylene and its relationship with anthocyanin and flavonoid concentrations and color development in 'Pink Lady' apples would help plan management practices used by apple growers for improving color, which in turn would have a positive impact on fruit quality, nutrition at harvest, and after-storage.

Although flavonoid composition of various apple cultivars has been measured during development and ripening, it has not been documented in 'Pink Lady' apple, a promising new commercial Australian cultivar. Therefore the objectives of this study were 1) to monitor the development of color and changes in endogenous ethylene concentration during fruit development and ripening; 2) to identify, monitor, and quantify the flavonoid and phenolic profile in the fruit skin, including flavanols, quercetin glycosides, chlorogenic acid, phloridzin, and anthocyanins during fruit development and ripening; and 3) to elucidate the relationships 
between endogenous ethylene and color development, and between endogenous ethylene and the different flavonoids during the entire fruit growth and maturation period.

\section{Materials and Methods}

Plant materials. 'Pink Lady' apple trees grown in Carmel, Western Australia (lat. $31^{\circ} 57^{\prime} \mathrm{S}$; long. $115^{\circ} 50^{\prime} \mathrm{E}$ ) were selected for these experiments during 2002 to 2003 and 2003 to 2004. Trees were grafted on M.M.109 rootstock and planted in 1997 in the east-west direction in blocks, maintaining row distances of $5 \mathrm{~m}$ and plant distances of $2.5 \mathrm{~m}$.

Fruit SAMPLing. In both years, 25 to 50 fruit (depending on the fruit growth stage) were picked randomly from all parts of the tree canopy up to a height of $2 \mathrm{~m}$ from the ground at several dates during fruit growth and maturation. In 2002 to 2003, fruit sampling commenced $60 \mathrm{~d}$ after full bloom (DAFB), and subsequent fruit sampling was conducted on $88,109,131,144,158$, $164,171,179$, and 189 DAFB. Commercial harvest in 2002 to 2003 corresponded to 189 DAFB. In 2003 to 2004, the same row of trees as in the previous season was used for the trial. However, fruit sampling commenced on 7 DAFB and continued for 4 weeks after the commercial harvest date. The sampling dates were on $7,18,38,58,78,99,119,140,154,161,168,175,182$, $187,194,201,208$, and 215 DAFB. Commercial harvest during 2003 to 2004 corresponded to 187 DAFB. Full bloom $(>80 \%$ of the buds are open) for the 2002 to 2003 season occurred on 20 Oct. 2002, and for the 2003 to 2004 season it occurred on 20 Oct. 2003. The experimental design was a randomized complete block design. Two trees were selected as an experimental unit and were replicated three times. To minimize the thinning effect resulting from continuous sampling during the fruiting season, different trees within the row were selected at each sampling date.

Fruit GROWTH. Fruit growth parameters, including fruit diameter, length, and fresh weight, were recorded from 20 individual fruit per replicate during fruit growth and maturation at various intervals as mentioned earlier.

Fruit COLOR. Percent blush on fruit surface was assessed visually on individual fruit (20 fruit per replicate) and scores were given on a percentage basis from $0 \%$ to $100 \%$. Zero percent represented no red blush whereas $100 \%$ represented a fully red apple. The color requirement for export markets are set at not less than $40 \%$ bright-pink blush on a cream pale-green background for 'Pink Lady' apple (Department of Agriculture Western Australia, 2000). Fruit color (20 fruit per replicate) was also recorded from four positions along the equatorial region of the fruit in Commission Internationale de L'Eclairage units using a HunterLab ColorFlex $45^{\circ} / 0^{\circ}$ Spectrophotometer (HunterLab ColorFlex; Hunter Associates, Reston, Va.) as L*, $a^{*}$, and $b^{*}$ color coordinates on the fruit surface (Hunter, 1975; McGuire, 1992). The data were expressed in hue angle, which was calculated as $\tan ^{-1} \mathrm{~b}^{*} / \mathrm{a}^{*}$ (McGuire, 1992). Hue angle, which is the most appropriate way of representing changes in color, refers to the line from the origin to the intercept of $\mathrm{a}^{*}$ (x-axis) and $\mathrm{b}^{*}$ (y-axis) coordinates, where $0^{\circ}=$ red, $90^{\circ}=$ yellow, $180^{\circ}=$ green, and $270^{\circ}=$ blue (McGuire, 1992).

ETHYLENE ESTimation. Endogenous ethylene was extracted under vacuum using the methods outlined by Beyer and Morgan (1970) and Saltveit (1982). Fruit were submerged under saturated ammonium sulfate solution in a desiccator and a constant vacuum of $92 \mathrm{kPa}$ was applied for $6 \mathrm{~min}$. At the end of the extraction period, $1 \mathrm{~mL}$ gas was drawn out and immediately injected into a gas chromatograph (6890 N Network GC system; Agilent Technologies, Palo Alto, Calif.) fitted with a 2-m-long stainless steel Supelco Porapak-Q column (o.d., 3.175 mm; mesh size, 80/100; Supelco, Bellefonte, Pa.) and a flame ionization detector. Nitrogen was used as the carrier gas. The column temperature was maintained at $110{ }^{\circ} \mathrm{C}$ (isothermal), injector temperature at $100{ }^{\circ} \mathrm{C}$, and detector temperature at $250{ }^{\circ} \mathrm{C}$.

AnAlysis of SKIn PIGMenTs. Skin was removed from 20 fruit per replication using a peeler, and any underlying tissue was scraped off. The skin was finely chopped and stored in a freezer $\left(-20^{\circ} \mathrm{C}\right)$ before analysis.

Total ANTHOCYANIN ANALYSIS. Total anthocyanin was estimated according to the method of Bishop and Klein (1975), with some modifications. Total anthocyanin was extracted by soaking fruit skin $(1 \mathrm{~g})$ in $10 \mathrm{~mL}$ aqueous methanol $(95 \%)$ to concentrated $\mathrm{HCl}$ in the ratio $(97: 3 \mathrm{v} / \mathrm{v})$ overnight at 2 to $4{ }^{\circ} \mathrm{C}$ in the dark. The resulting solution was decanted and centrifuged at $3963 g_{n}$ for $20 \mathrm{~min}$, and anthocyanin absorbance (1-cm light path) was determined from the supernatant solution at $530 \mathrm{~nm}$ using a ultraviolet/Vis spectrophotometer (model 6405; Jenway Spectrophotometers, Dunmow, Essex, UK). Total anthocyanin concentration was determined using a molar extinction coefficient of $3.43 \times 10^{4}$ for idaein chloride (Siegelman and Hendricks, 1958).

Chlorophyll analysis. Chlorophyll pigments were extracted using the method outlined by Lancaster et al. (1997), with some modifications. Skin (1 g) was homogenized using a Diax 900 homogenizer (Heidolph Instruments LLC, Cinnaminson, N.J.) in $15 \mathrm{~mL}$ acetone. The residue was re-extracted three times with $5 \mathrm{~mL} 80 \% \mathrm{v} / \mathrm{v}$ acetone. The extracts were combined and the volume was adjusted to $30 \mathrm{~mL}$ with $80 \% \mathrm{v} / \mathrm{v}$ acetone. The extracts were centrifuged at $1067 g_{n}$ for $20 \mathrm{~min}$ and the absorbances of the supernatant solution (1-cm light path) were recorded at 645, 652, and $663 \mathrm{~nm}$ using the ultraviolet/Vis spectrophotometer. Concentrations of chlorophyll $a$, chlorophyll $b$, and total chlorophyll were calculated using the equations of Maclachlan and Zalik (Holden, 1965).

Flavonoids and PHENOLIC COMPOUnds. Flavonoids and phenolic compounds were extracted by the method outlined by Awad and de Jager (2000), with some modifications. Flavanols (catechin and epicatechin), quercetin glycosides, and anthocyanins were extracted from fruit skin $(0.5 \mathrm{~g})$ by sonication in $20 \mathrm{~mL} \mathrm{100 \%} \mathrm{methanol} \mathrm{:} \mathrm{10 \%} \mathrm{(v/v)} \mathrm{acetic} \mathrm{acid}$ $(85: 15 \mathrm{v} / \mathrm{v})$ for $30 \mathrm{~min}$. After sonication, the solution was rotary evaporated under vacuum to near dryness at $35{ }^{\circ} \mathrm{C}$ using a Buchi Rotavapor (BÜCHI Labortechnik AG, Flawil, Switzerland). The extract was redissolved in $1 \mathrm{~mL} 100 \%$ methanol and $6 \mathrm{~mL}$ acetic acid $(10 \% \mathrm{v} / \mathrm{v})$, sonicated for $1 \mathrm{~min}$, and centrifuged at $2963 g_{\mathrm{n}}$ for $15 \mathrm{~min}$ at $4{ }^{\circ} \mathrm{C}$. The supernatant volume was made up to $25 \mathrm{~mL}$ with acetic acid $(10 \% \mathrm{v} / \mathrm{v})$ and filtered through a $0.22-\mu \mathrm{m}$ syringe filter.

Flavonoid composition in the filtered extract was analyzed by reverse phase high-performance liquid chromatography (HPLC). A $20-\mu \mathrm{L}$ sample was injected into the HPLC system (Waters 1525 Binary HPLC Pump fitted to Waters 2487 Dual Wavelength Absorbance Detector and Waters 717plus Autosampler; Waters Corp., Milford, Mass.) equipped with a $\mathrm{C}_{18}$ column (Waters Symmetry- $\mathrm{C}_{18}, 150 \times 4.6 \mathrm{~mm}$ i.d.; $5 \mu \mathrm{m}$ packaging). The column was preceded by a Symmetry $\mathrm{C}_{18}$ guard column of the same stationary phase. Solvents used for elution were $10 \%(\mathrm{v} / \mathrm{v})$ acetic acid in distilled water (A) and $100 \%$ methanol (B). The column and guard column were maintained at $35^{\circ} \mathrm{C}$ and the solvent flow rate was $1.0 \mathrm{~mL} \cdot \mathrm{min}^{-1}$. 
Elution was achieved in 35 min using the following gradient program: $100 \% \mathrm{~A}$ as the initial condition, then a linear gradient to $80 \% \mathrm{~A}$ and $20 \% \mathrm{~B}$ for $20 \mathrm{~min}$, which was held for $10 \mathrm{~min}$. The system was returned to $100 \%$ A from 30 to $31 \mathrm{~min}$ and equilibrated from 31 to $35 \mathrm{~min}$ before the next injection. Catechin, epicatechin, chlorogenic acid, and phloridzin were monitored at $280 \mathrm{~nm}$; quercetin glycosides (quercetin 3-galactoside, quercetin 3 rutinoside, quercetin 3-glucoside, quercetin 3-rhamnoside quercetin 3-arabinoside and quercetin 3 -xyloside) at $350 \mathrm{~nm}$; and anthocyanins (cyanidin 3-galactoside) at $530 \mathrm{~nm}$. All analyses were done in duplicate.

HPLC PEAK IDENTIFICATION AND QUANTIFICATION. Different flavonoids in the samples were identified by comparing their retention times with those of authentic standards and also by co-chromatography involving spiking with the corresponding standard solutions of known concentrations. Compounds were quantified from integrated areas of the sample and the corresponding standard of known quantity and expressed on a fresh weight (FW) basis. All standards were prepared in $10 \mathrm{~mL}$ methanol : $10 \%(\mathrm{v} / \mathrm{v})$ acetic acid $(85: 15 \mathrm{v} / \mathrm{v}) .(+)$ Catechin, quercetin 3-glucoside, quercetin 3-rhamnoside, and quercetin 3-galactoside were purchased from Carl Roth (Karlsruhe, Germany), chlorogenic acid from Sigma (Castle Hill, Australia), phloridzin dihydrate and (-) epicatechin from Fluka (Castle Hill, Australia), quercetin 3-rutinoside from ICN Biomedicals Inc. (Girraween, Australia), quercetin 3-arabinoside and quercetin 3 -xyloside from Apin Chemicals Limited (Abingdon, UK), and cyanidin 3-galactoside from Extrasynthese (Genay, France).

Statistical analysis. Data were subjected to analysis of variance using Genstat 6 (release 6.2; Lawes Agricultural Trust, Rothamsted Expt. Sta., Harpenden, UK). Least significant differences (Fisher's protected LSD) were calculated at $P \leq$ 0.05 after significant $F$ tests. Spearman's rank correlation was calculated using Genstat 6 to determine the association between ethylene and percent red blush and between ethylene and the different flavonoids. Spearman's rank correlation was used because ethylene was not detected during the middle of the growth season. Unless otherwise specified, all the significant differences are for $P \leq 0.05$.

\section{Results and Discussion}

FruIT GRowth. The fruit development period can be divided into four physiological phases: I, 0 to 35 DAFB, when growth was characterized by cell division (fruitlet stage); II, 36 to 180 DAFB, the main fruit growth and development stage characterized by cell enlargement; III, 181 to 190 DAFB, the maturation phase; and IV, 191 DAFB and beyond corresponding to fruit ripening. Increase in fruit diameter (Fig. 1A) and FW (Fig. 1C) showed single sigmoid growth patterns, whereas fruit length (Fig. 1B) increased linearly throughout the growing season in both years. Similar sigmoidal and slight sigmoidal growth patterns were reported for increase in dry weight in 'Jonagold' and 'Elstar' apples respectively (Awad et al., 2001). In apple, the first 35 to 45 DAFB is generally characterized by cell division followed by vacuolation of the cells, an increase in individual cell size, and finally an increase in intercellular spaces (Warrington et al., 1999). Differences in fruit diameter during the two season were minor, although during 2003 to 2004, fruit had a slightly larger diameter compared with 2002 to 2003 during the maturation stage. Fruit length was greater in 2003 to 2004 compared with 2002 to 2003 during the

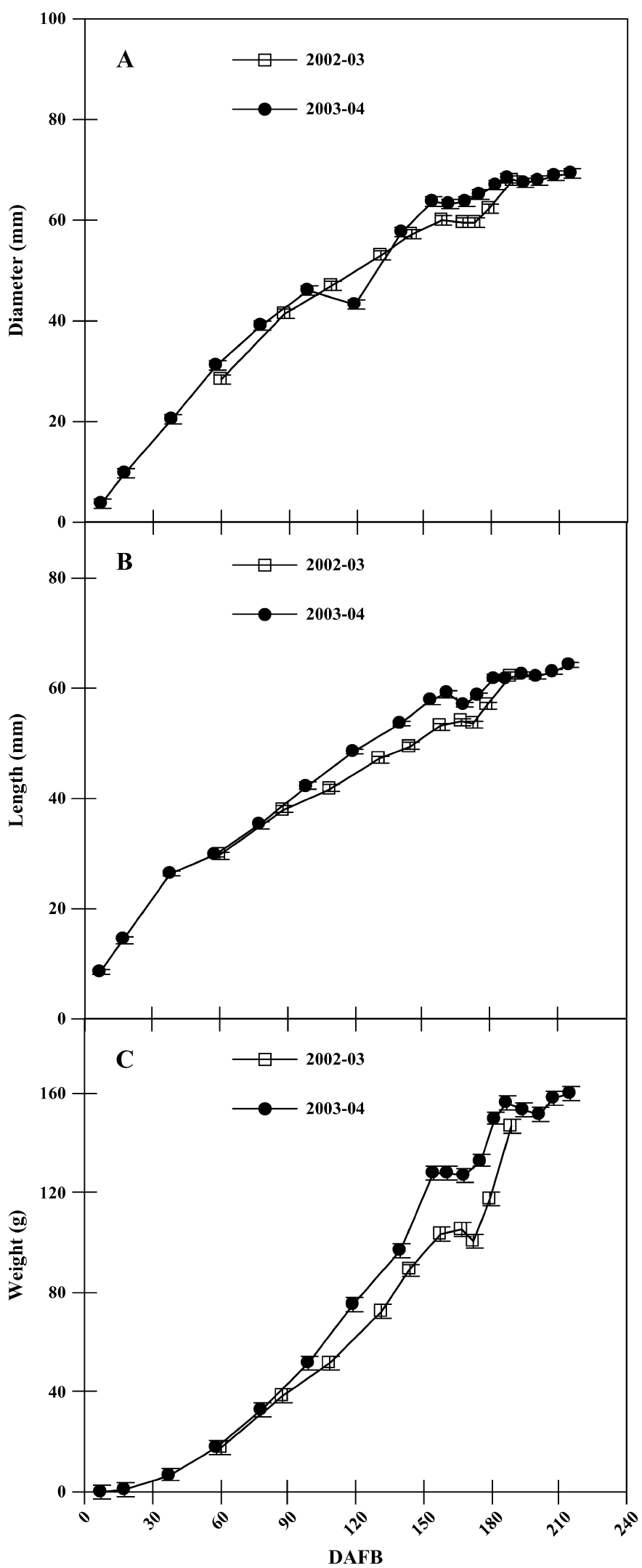

Fig. 1. Changes in fruit diameter (A), length (B), and FW (C) of 'Pink Lady' apple during development and ripening in 2002 to 2003 and 2003 to 2004 ( $\mathrm{n}=$ 60; three replications, 20 fruit per replication). LSD $(P \leq 0.05)$ for 2002 to 2003: diameter, 2.8; length, 1.9; and FW, 8.2. LSD $(P \leq 0.05)$ for 2003 to 2004: diameter, 2.4; length, 1.5; FW, 7.8. Vertical bars represent SE. When vertical bars are not visible, SE is smaller than the symbols. DAFB ( $\mathrm{d}$ after full bloom). 
developmental stages, but was similar in both seasons as the fruit approached commercial harvest. Fruit weight during 2003 to 2004 was greater during the developmental and ripening stages compared with the previous season.

ENDOGENOUS ETHYLENE. In 2003 to 2004, during the early fruit growth stages (7-38 DAFB), endogenous ethylene concentration was significantly high, and two peaks were recorded at 7 and 38 DAFB (Fig. 2). This was followed by a steady decline from 99 to 154 DAFB when ethylene was almost undetectable. Commencing from 161 DAFB there was an increase in ethylene production building to a peak at 208 DAFB. There was a 3.5-fold increase in ethylene concentration in fruit harvested on 208 DAFB compared with fruit harvested at commercial harvest (187 DAFB), which indicates the commencement of the climacteric phase. However, during 2002 to 2003, the ethylene concentration during development and ripening was low to undetectable between 60 DAFB and 189 DAFB. Because sampling in 2002 to 2003 commenced at 60 DAFB and stopped at commercial harvest (189 DAFB), the characteristic increases in ethylene concentration during fruitlet and maturation stages were probably missed. The pattern of changes in endogenous ethylene observed during 2003 to 2004 is typical of apple fruit and has also been reported by Bufler (1986), Little and Holmes (2000), and Walsh and Solomos (1987). Increased ethylene during the fruitlet stage may be attributed to rapid cell division occurring during this period. Walsh and Solomos (1987) suggested that increased ethylene production in fruitlets during the first 30 to $40 \mathrm{~d}$ of fruit growth was promoted by plant hormones regulating cell division in the flesh and seeds, and high auxin levels in these tissues further stimulated ethylene production. Bufler (1986) reported that in mature apples, ethylene increased in an exponential manner, which could be the result of increased sensitivity of the tissues to ethylene or an increase in the number of ethylene receptors.

Fruit COLOR. During the 2003 to 2004 season, there were two periods of red color development on the fruit surface. The first peak occurred at 7 DAFB, with more than $20 \%$ of the fruitlet surface exhibiting bronze-red coloration; the appear-

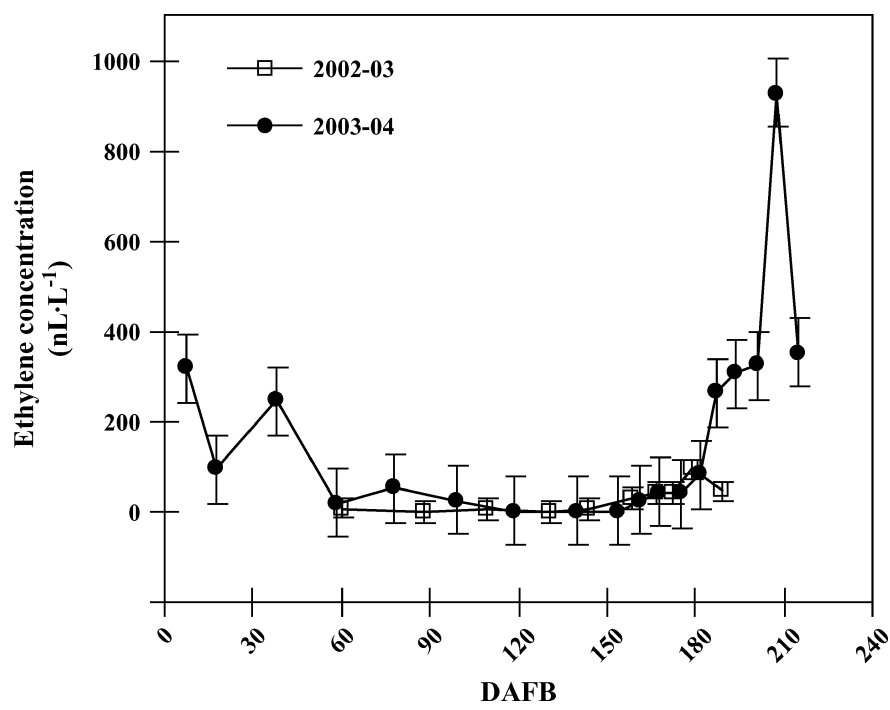

Fig. 2. Changes in endogenous ethylene concentration of 'Pink Lady' apple during development and ripening in 2002 to 2003 and 2003 to 2004 ( $\mathrm{n}=12$; three replications, four fruit per replication). LSD $(P \leq 0.05)$ for 2002 to 2003: NS. For 2003 to 2004: 216.6. Vertical bars represent SE. DAFB (d after full bloom). ance of the second peak commenced during fruit maturation ( $\geq 168$ DAFB; Fig. 3A). These two peaks of red color development in apple have also been reported in other apple cultivars such as 'Jonagold' and 'Elstar' (Awad et al., 2001), and 'Fuji' (Li et al., 2002). Commencing from 168 DAFB, percent blush increased from $16 \%$ to $44 \%$ at commercial harvest (187 DAFB), and this increasing trend continued until 215 DAFB, when more than $90 \%$ of the fruit surface exhibited red color. In 2002 to 2003, however, when sampling commenced on $60 \mathrm{DAFB}$, the initial red color had begun to disappear and the fruit remained green until 172 DAFB, when there was a significant increase in red blush development (Fig. 3A). The changes in color development including the two periods of increased red color appearance on the fruit surface paralleled the changes in endogenous ethylene concentration in the fruit. In both the 2002 to 2003 and 2003 to 2004 growing seasons, endogenous ethylene concentration of fruit was

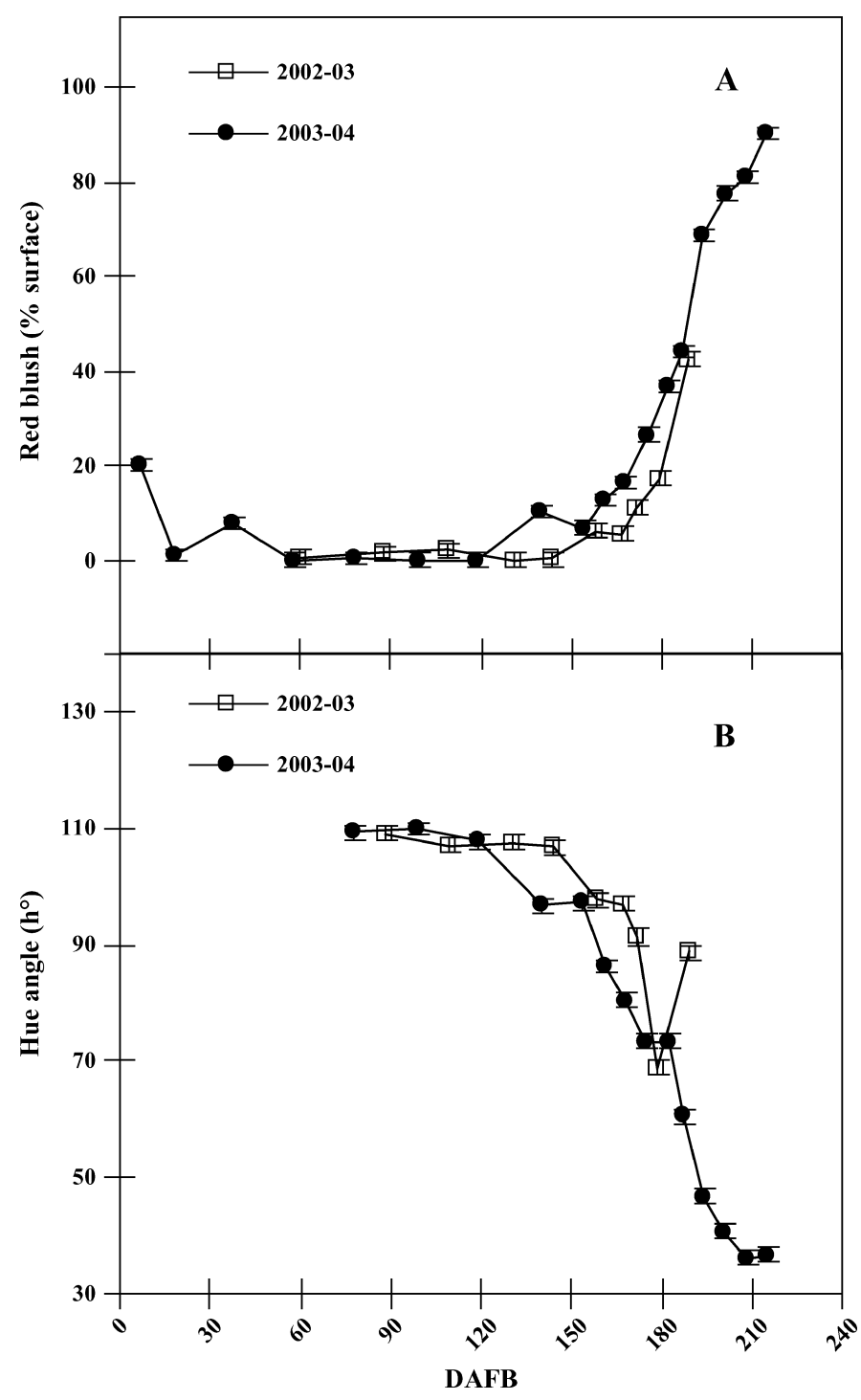

Fig. 3. Changes in visual color (A) and hue angle (B) of 'Pink Lady' apple during development and ripening in 2002 to 2003 and 2003 to 2004 ( $\mathrm{n}=60$; three replications, 20 fruit per replication). LSD $(P \leq 0.05)$ for 2002 to 2003: hue angle, 3.9; visual color, 4.6. LSD $(P \leq 0.05)$ for 2003 to 2004: hue angle, 3.4; visual color, 3.9. Vertical bars represent SE. When vertical bars are not visible, sE is smaller than the symbols. DAFB ( $\mathrm{d}$ after full bloom). 
significantly and positively $(P \leq 0.001)$ correlated with development of red blush $\left(r_{\mathrm{s}}=0.71\right.$ and 0.70 respectively; Table 1$)$.

Hue angle (change in color from green to red) followed similar trends in both growing seasons and was relatively constant between 88 to 144 DAFB in 2002 to 2003 and between 78 to 119 DAFB during 2003 to 2004 (Fig. 3B). The decline in hue angle occurred rapidly during fruit maturation in both 2002 to 2003 and 2003 to 2004 , especially as the fruit approached commercial harvest corresponding to the increase in red blush development. During 2003 to 2004, hue angle continued to decrease after the date for commercial harvest had passed, and at 215 DAFB had reduced by almost $27^{\circ}$ compared with fruit harvested at commercial harvest. In both years, there was a significant negative correlation $(P \leq 0.001)$ between endogenous ethylene and hue angle $\left(r_{\mathrm{s}}=-0.79\right.$ in 2002 to 2003 and -0.81 in 2003 to 2004 ; Table 1 ).

IDENTIFICATION OF FLAVONOIDS AND PHENOLIC COMPOUNDS. Eleven flavonoid compounds belonging to five major polyphenolic groups were identified in the fruit skin using HPLC (Fig. 4). These included catechin and epicatechin (flavanols); chlorogenic acid (hydroxycinnamic acid) and phloridzin (dihydrochalcone) (Fig. 4A); quercetin 3-galactoside, quercetin 3 xyloside, quercetin 3-rutinoside, quercetin 3-glucoside, quercetin 3-arabinoside and quercetin 3-rhamnoside (flavonols); (Fig. 4B) and cyanidin 3-galactoside (anthocyanin) (Fig. 4C).

Changes in Pigment Concentrations. The development of red blush and the reduction in hue angle coincided with the increase in concentrations of total anthocyanin (Fig. 5A) and cyanidin 3-galactoside (Fig. 5B), and the decrease in concentration of chlorophylls (Fig. 6) in fruit skin in both years. In both the 2002 to 2003 and 2003 to 2004 seasons, endogenous ethylene concentration of fruit was significantly correlated $(P \leq 0.001)$ with total anthocyanin concentration $\left(r_{\mathrm{s}}=0.70\right.$ and 0.80 respectively) and cyanidin 3 -galactoside concentration $\left(r_{\mathrm{s}}=0.73\right.$ and 0.76 respectively; Table 1$)$. Therefore, the development of red color during these phases can be ascribed to increased anthocyanin concentration and to the loss of chlorophyll as well. The accumulation of anthocyanins during these phases

Table 1. Relationship between endogenous ethylene and development of red blush, hue angle, and concentrations of flavonoids in 'Pink Lady' apple during 2002 to 2003 and 2003 to 2004.

\begin{tabular}{lcc}
\hline & \multicolumn{2}{c}{$\begin{array}{c}\text { Spearman's rank } \\
\text { correlation }\left(r_{\mathrm{s}}\right)\end{array}$} \\
\cline { 2 - 3 } Variables compared & $2002-2003$ & $2003-2004$ \\
\hline Ethylene vs. percent red blush & $0.71^{* * *}$ & $0.70^{* * *}$ \\
Ethylene vs. total anthocyanin & $-0.70^{* * * *}$ & $0.80^{* * *}$ \\
Ethylene vs. hue angle & $0.73^{* * *}$ & $-0.81^{* * *}$ \\
Ethylene vs. cyanidin 3-galactoside & $\mathrm{NS}$ & $0.76^{* * *}$ \\
Ethylene vs. chlorogenic acid & $-0.55^{* * *}$ & $0.66^{* * *}$ \\
Ethylene vs. phloridzin & $\mathrm{NS}$ & $-0.28^{*}$ \\
Ethylene vs. catechin & $\mathrm{NS}$ & $\mathrm{NS}$ \\
Ethylene vs. epicatechin & $\mathrm{NS}$ & $\mathrm{NS}$ \\
Ethylene vs. quercetin 3-arabinoside & $0.38^{*}$ & $\mathrm{NS}$ \\
Ethylene vs. quercetin 3-galactoside & $-0.57^{* * *}$ & $\mathrm{NS}$ \\
Ethylene vs. quercetin 3-glucoside & $\mathrm{NS}$ & $\mathrm{NS}$ \\
Ethylene vs. quercetin 3-rhamnoside & $\mathrm{NS}$ & $\mathrm{NS}$ \\
Ethylene vs. quercetin 3-xyloside & $-0.48^{* * *}$ & $\mathrm{NS}$ \\
Ethylene vs. quercetin 3-rutinoside & $\mathrm{NS}$
\end{tabular}

$\overline{\mathrm{Ns}, *, * *, * * *}$ Nonsignificant or significant at $P \leq 0.05,0.01$, or 0.001 respectively.

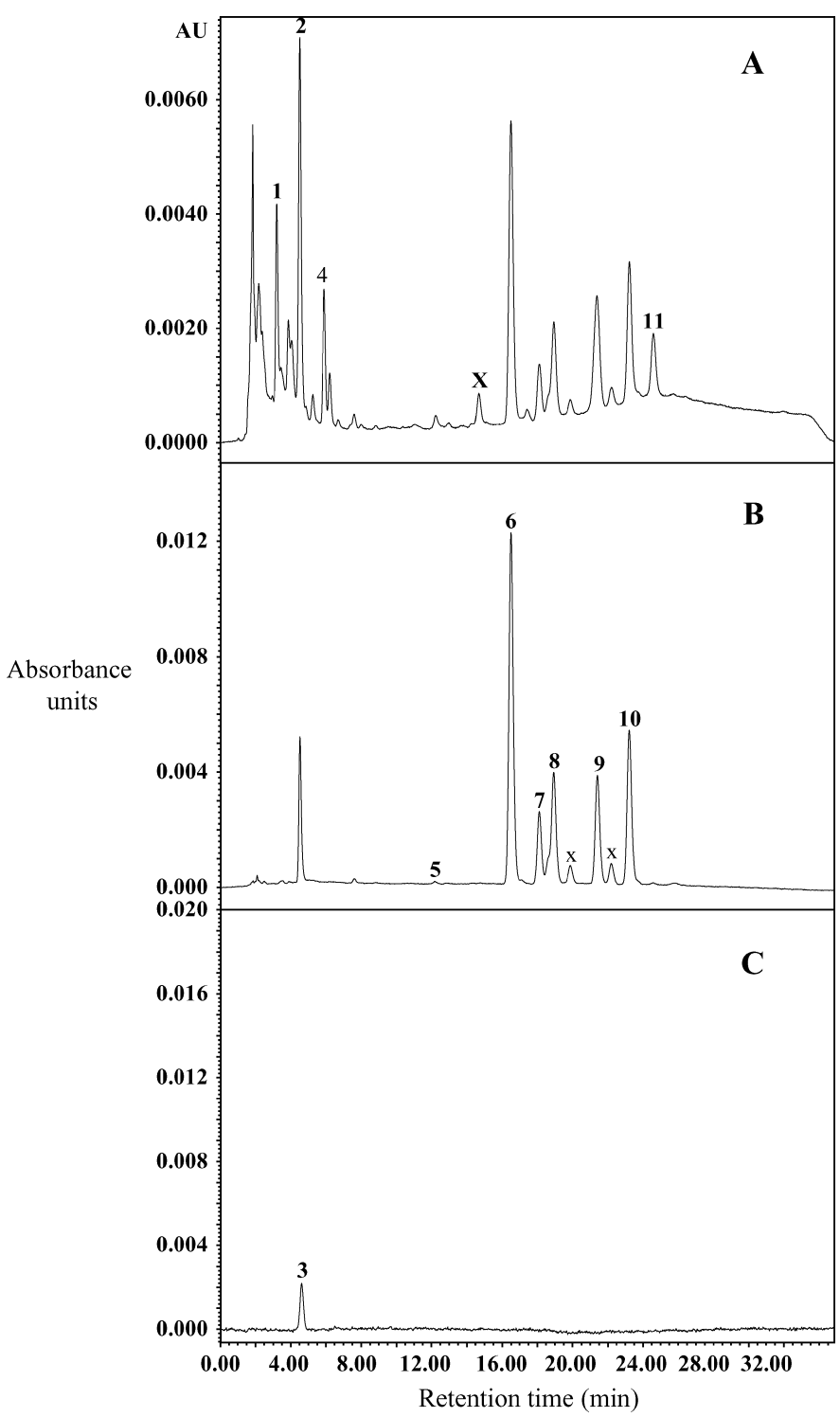

Fig. 4. Chromatographic profile of flavonoids and phenolic compounds in the skin of mature 'Pink Lady' apple. (A) Compounds monitored at $280 \mathrm{~nm}$. (B) Flavonols monitored at $350 \mathrm{~nm}$. (C) Anthocyanins monitored at $530 \mathrm{~nm}$. 1, catechin; 2, chlorogenic acid; 3, cyanidin 3-galactoside; 4, epicatechin; 5, quercetin 3-xyloside; 6, quercetin 3-galactoside; 7, quercetin 3-glucoside; 8, quercetin 3-rutinoside; 9, quercetin 3-arabinoside; 10, quercetin 3-rhamnoside; 11, phloridzin; $\mathrm{x}$, unidentified compound; AU, absorbance units.

appears to be associated with the increased concentration of endogenous ethylene. Positive correlations between ethylene and color development, ethylene and anthocyanin accumulation in skin, and a negative correlation between ethylene and hue angle support the previously mentioned hypothesis (Table 1). In addition, color development and anthocyanin accumulation in 'Pink Lady' apple were enhanced with exogenous applications of ethephon (an ethylene-releasing compound) and were retarded by the aminoethoxyvinylglycine (an ethylene inhibitor) when applied 4 to 5 weeks before commercial harvest (data not shown). In apple, ethylene has been widely reported to regulate the development of blush and the accumulation of anthocyanin in the skin (Faragher and Brohier, 1984; Kondo et al., 1991; Murphey and Dilley, 1988). Increased activities of the anthocyanin biosynthetic pathway enzymes such as chalcone isomerase and phenylalanine 


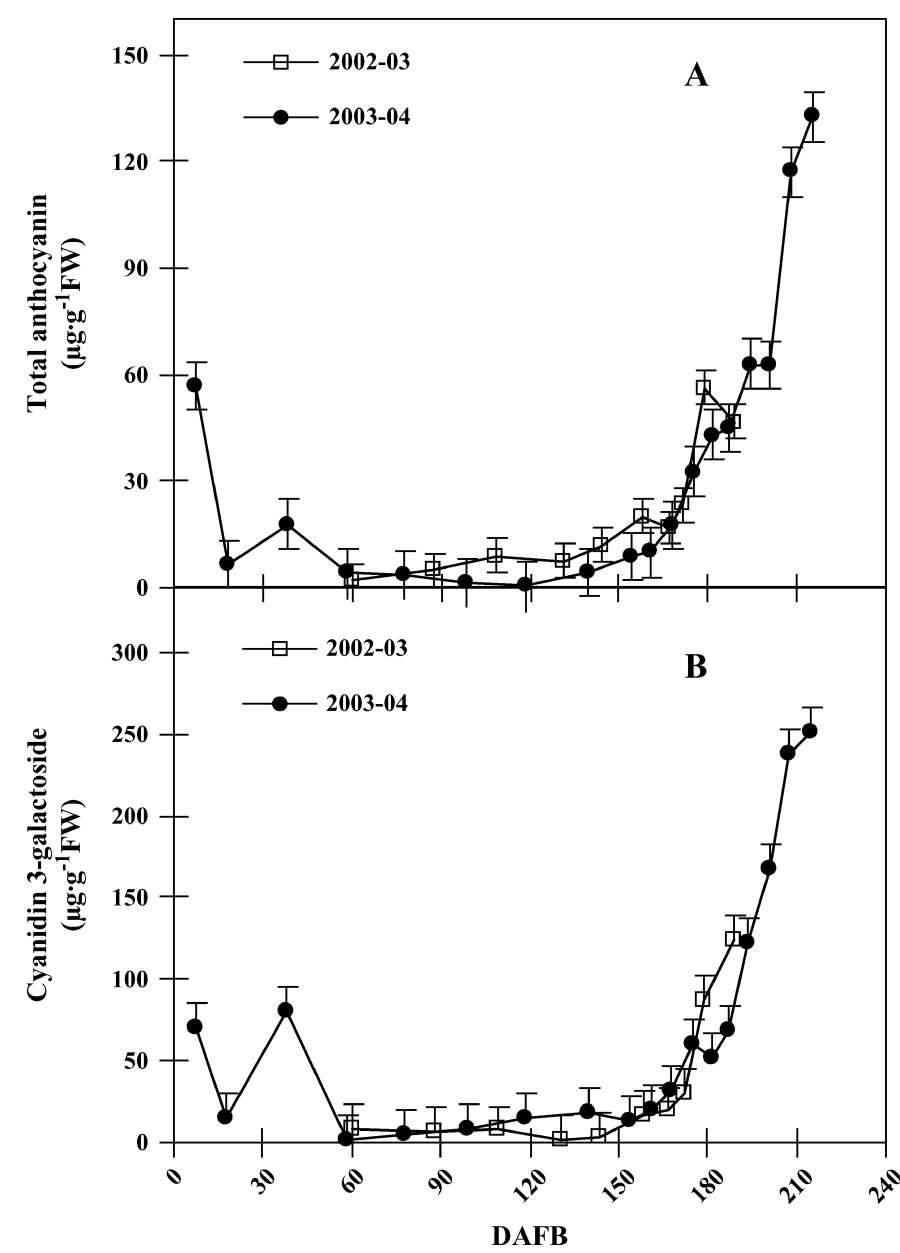

Fig. 5. Changes in concentrations of total anthocyanin (A) and cyanidin 3 -galactoside (B) in the skin of 'Pink Lady' apple during development and ripening in 2002 to 2003 and 2003 to 2004 (three replications). LSD $(P \leq 0.05)$ for 2002 to 2003: total anthocyanin, 14.1; cyanidin 3-galactoside, 30.8. LSD $(P \leq 0.05)$ for 2003 to 2004: total anthocyanin, 19.5; cyanidin 3-galactoside, 42.7. Vertical bars represent SE. DAFB (d after full bloom).

ammonia-lyase (PAL) during early fruitlet and maturation stages may have also regulated anthocyanin accumulation during these periods, because chalcone isomerase and PAL enzymes are reported to be closely associated with anthocyanin accumulation in apple (Faragher and Brohier, 1984; Li et al., 2002). In 'Red Delicious' apple, ethylene is considered to stimulate PAL activity, because ethylene concentration and activity of PAL enzyme increased simultaneously (Blankenship and Unrath, 1988).

Concentrations of chlorophylls $a$ and $b$, and total chlorophyll were highest during the early stages of growth and declined during development and ripening to very low concentrations (Fig. 6). During 2003 to 2004, chlorophyll $a$ concentration at 215 DAFB was $6.1 \mu \mathrm{g} \cdot \mathrm{g}^{-1} \mathrm{FW}$ (Fig. 6A), whereas chlorophyll $b$ was $4.0 \mu \mathrm{g} \cdot \mathrm{g}^{-1} \mathrm{FW}$ (Fig. 6B). In 2002 to 2003, chlorophyll $a$ and $b$ concentrations at commercial harvest (189 DAFB) were 18.8 and $7.8 \mu \mathrm{g} \cdot \mathrm{g}^{-1} \mathrm{FW}$ respectively (Fig. 6A and B). This pattern of change in chlorophyll concentration is characteristic of apple fruit ripening (Knee, 1972). The ratio between total chlorophyll and total anthocyanin showed an increasing trend from the beginning of the season and peaked between 99 and $119 \mathrm{~d}$ in 2003 to 2004. Thereafter, there was steep decline in the ratio as the skin accumulated higher concentrations of anthocyanin, and

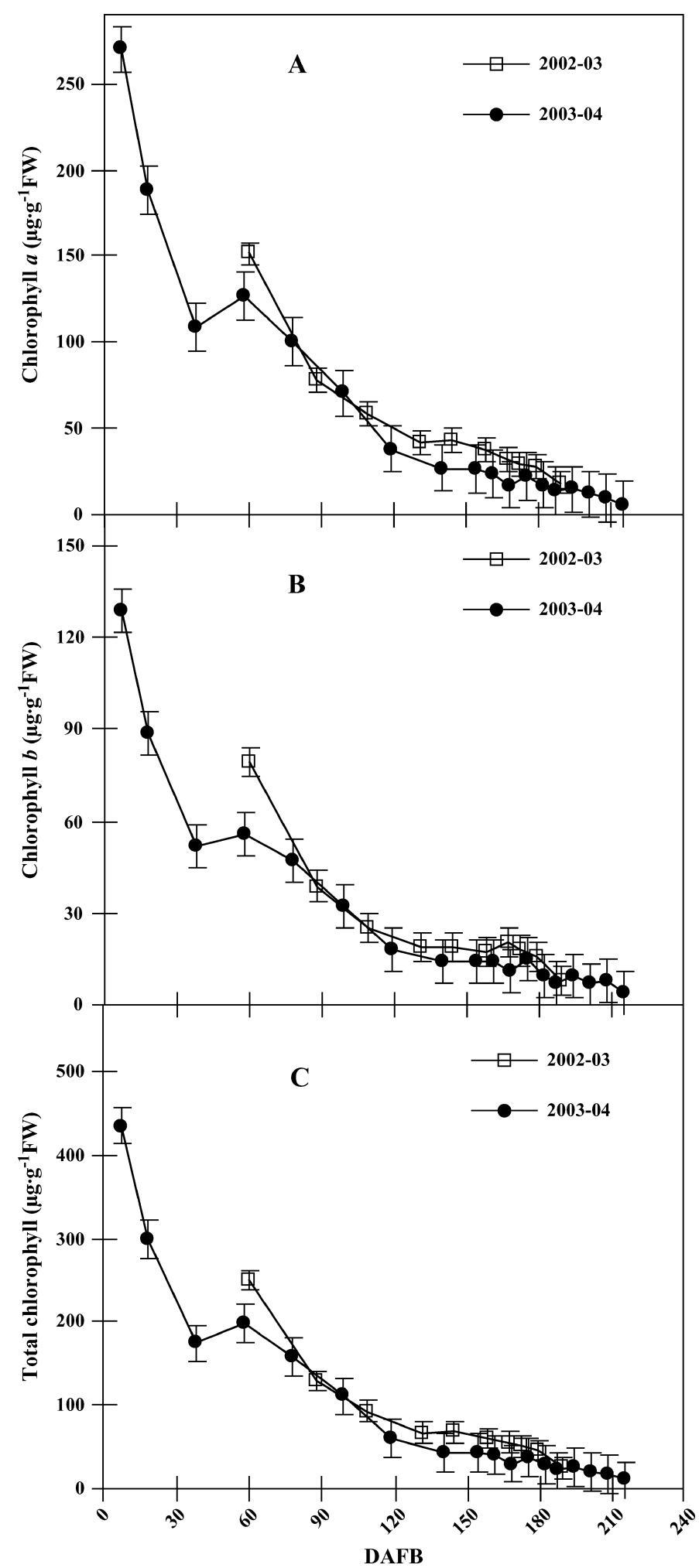

Fig. 6. Changes in concentrations of chlorophyll $a(\mathbf{A})$, chlorophyll $b(\mathbf{B})$, and total chlorophyll $(\mathbf{C})$ in the skin of 'Pink Lady' apple during development and ripening in 2002 to 2003 and 2003 to 2004 (three replications). LSD $(P \leq 0.05)$ for 2002 to 2003: chlorophyll $a$, 20.1; chlorophyll $b, 14.4$; total chlorophyll, 37.5. LSD ( $P \leq 0.05$ ) for 2003 to 2004: chlorophyll $a$, $=39.5$; chlorophyll $b$, 20.1; total chlorophyll, 64.2. Vertical bars represent SE. DAFB (d after full bloom). 


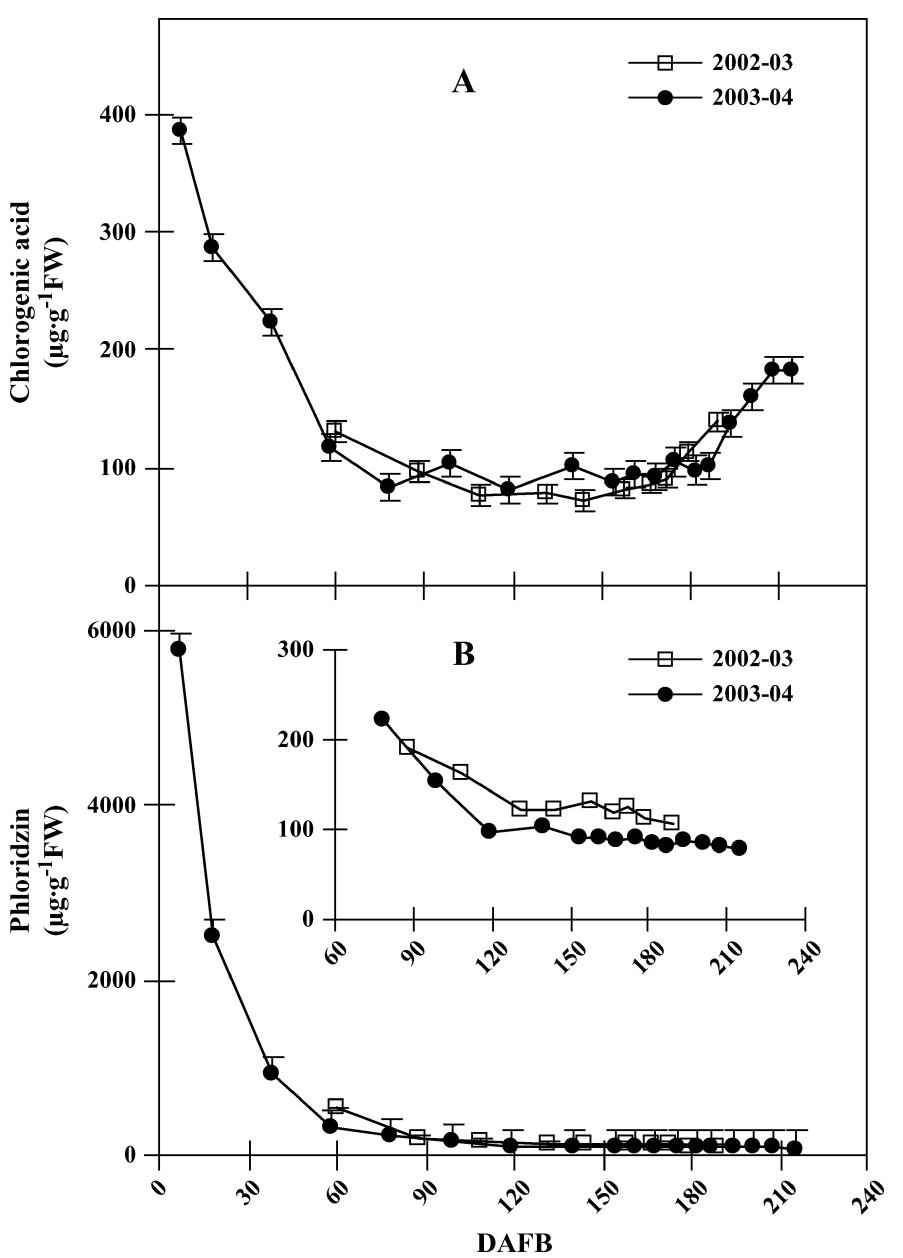

Fig. 7. Changes in concentrations of chlorogenic acid (A) and phloridzin (B) in the skin of 'Pink Lady' apple during development and ripening in 2002 to 2003 and 2003 to 2004 (three replications). LSD $(P \leq 0.05)$ for 2002 to 2003: chlorogenic acid, 24.7; phloridzin, 65.7. LSD $(P \leq 0.05)$ for 2003 to 2004: chlorogenic acid, 32.7; phloridzin, 557.4. Vertical bars represent SE. DAFB (d after full bloom). When vertical bars are not visible, SE is smaller than the symbols.

this also corresponded to increased ethylene production (data not shown). The decline in chlorophyll concentration during apple fruit ripening is associated with the disintegration of the photosynthetic units (conversion of chlorophlasts to chromoplasts, degradation of thylakoid membranes and formation of plastoglobuli), resulting in the increase in carotenoid pigments (Solovchenko et al., 2005). Increasing ethylene concentration during fruit ripening may also increase chlorophyllase and chlorophyll degrading peroxidase enzyme activities, resulting in the accumulation of chlorophyllide $a$. In 'Wase Satsuma' mandarins (Citrus unshu Marc.), exposure to ethylene gas increased chlorophyll degradation, which was ascribed to the formation of chlorophyllide $a$ by chlorophyllase enzyme (Yamauchi et al., 1997).

Flavonoids. During 2003 to 2004, apart from the first sampling date (7 DAFB), quercetin glycosides were the major flavonoids present in fruit skin throughout the developmental and ripening stages, whereas phloridzin was the most abundant flavonoid at 7 DAFB. Similar results have also been reported in 'Jonagold' and 'Elstar' apples (Awad et al., 2001).

Concentrations of chlorogenic acid (Fig. 7A), phloridzin (Fig. 7B), the flavanols catechin and epicatechin (Fig. 8), and

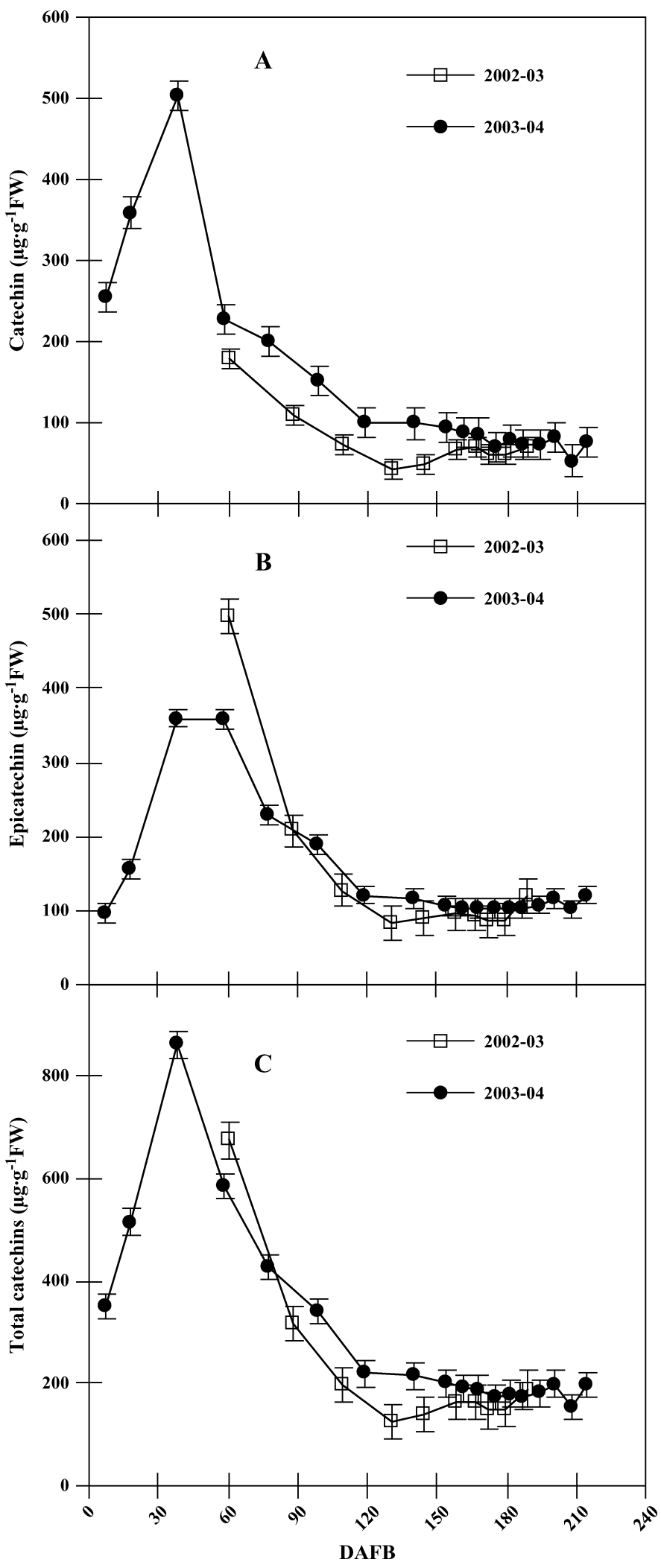

Fig. 8. Changes in concentrations of catechin (A), epicatechin (B), and total catechins $(\mathbf{C})$ in the skin of 'Pink Lady' apple during development and ripening in 2002 to 2003 and 2003 to 2004 (three replications). LSD $(P \leq 0.05)$ for 2002 to 2003: catechin, 35.8; epicatechin, 65.7; total catechins, 100.8. LSD $(P \leq 0.05)$ for 2003 to 2004: catechin, 53.1; epicatechin, 35.9; and total catechins, 72.9. Vertical bars represent SE. DAFB (d after full bloom). 
quercetin glycosides (Fig. 9) in the skin were higher during the early growth stages (7-60 DAFB) compared with the developmental and ripening stages $(\geq 60$ DAFB). This was more pronounced in the 2003 to 2004 season, when fruit sampling commenced on 7 DAFB and continued until 215 DAFB. The highest concentration of chlorogenic acid was recorded at the earliest stages of fruit growth (7-38 DAFB) during 2003 to 2004 , but gradually decreased during the developmental stages to a steady level followed by an increase during maturation and ripening ( $\geq 158$ DAFB during 2002 to 2003 and $\geq 168$ DAFB in 2003 to 2004; Fig. 7A). In general, after the initial peak, the concentrations of phloridzin, flavanols, and most quercetin glycosides decreased significantly, reaching stable levels during the developmental and ripening stages. Among the six quercetin glycosides identified, quercetin 3-galactoside and quercetin 3-arabinoside were the major flavonols in the skin in both years (Fig. 9A and B). During 2003 to 2004, quercetin 3 -arabinoside was the major quercetin glycoside in the skin between 7 and 119 DAFB. However, commencing from 140 DAFB, quercetin 3-galactoside was present in higher concentrations compared with quercetin 3-arabinoside, and this trend continued through maturation and ripening. In 2002 to 2003, quercetin 3-arabinoside was present in higher concentrations during the initial sampling dates (60 and 88 DAFB) and, from 109 DAFB, quercetin 3-galactoside accumulated in higher concentrations compared with quercetin 3-arabinoside. The ranking of the other four quercetin glycosides based on quantitative amounts was constant during the entire growth and development stage in both years and was as follows: quercetin 3-rhamnoside $>$ quercetin 3-rutinoside $>$ quercetin 3-glucoside $>$ quercetin 3-xyloside.

Although, the concentration of flavonoids decreased markedly from 60 DAFB, this does not indicate that the total amount of each flavonoid decreased in a similar trend. The decrease in concentration during development and ripening may be the result of the dilution of these compounds with the progression of fruit growth. Despite the dilution, the total amounts might have increased, which was masked because of the dominance of the growth of the apple (Fig. 2A and C). Awad et al. (2001) also suggested that the decrease in concentration of flavonoids and chlorogenic acid in apples was the result of dilution incited by progressive fruit growth.

The pattern of changes in the concentrations of chlorogenic acid, phloridzin, catechins, and quercetin glycosides in the fruit skin observed in this study has also been reported in other apple cultivars such as 'Elstar' and 'Jonagold' (Awad et al., 2001), and 'Golden Delicious' (Mayr et al., 1995). High concentrations of flavonols (catechin and epicatechin) in 'Pink Lady' fruitlets followed by decreasing concentrations during development and ripening (Fig. 8A and $\mathrm{B}$ ) have also been reported in 'Jonagold' and 'Elstar' (Awad et al., 2001), and 'Fuji' and 'Oorin' apples (Li et al., 2002).

A significant correlation was observed between ethylene and chlorogenic acid during 2003 to 2004, but not in 2002 to 2003
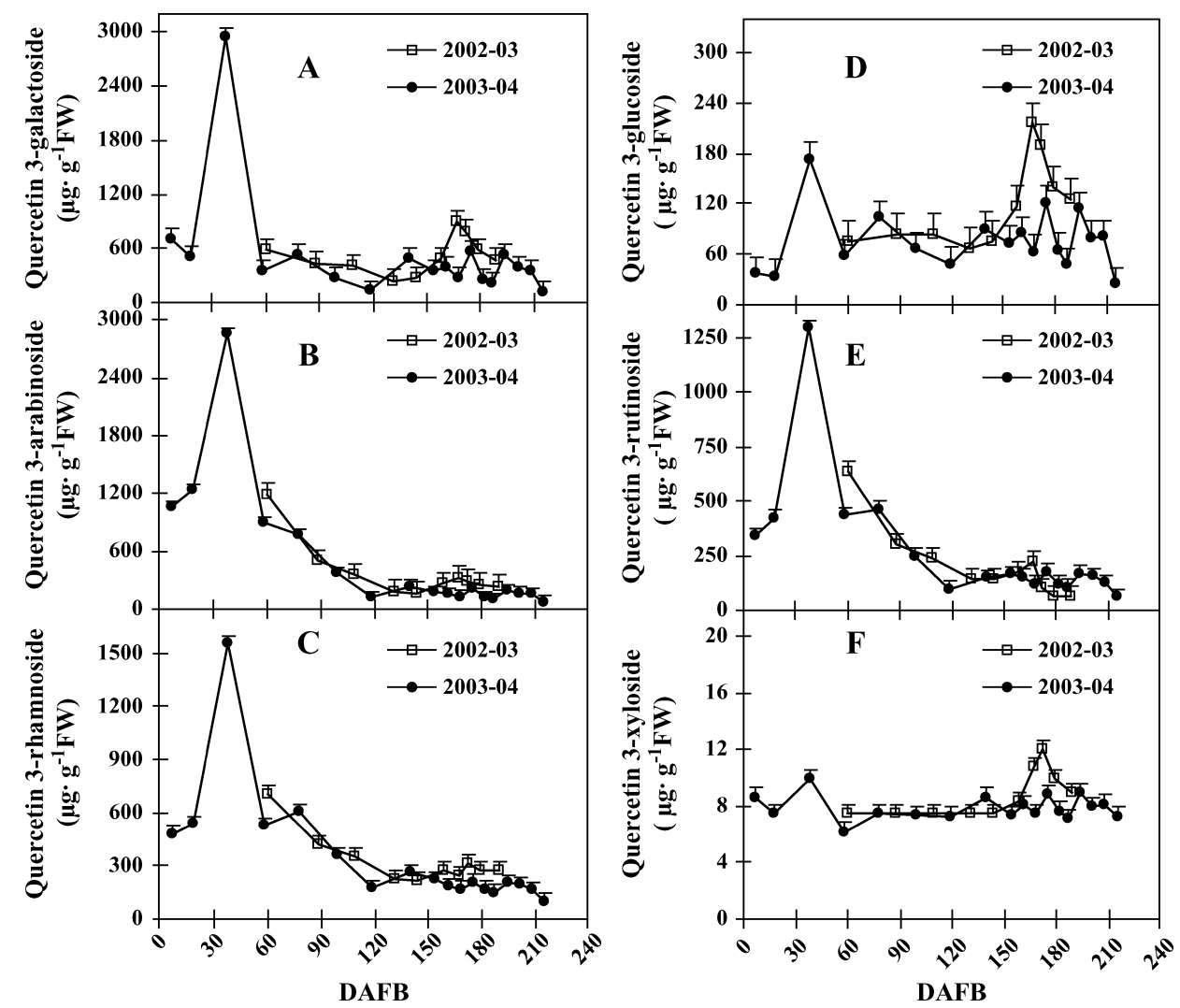

Fig. 9. Changes in concentrations of quercetin 3-galactoside (A), quercetin 3-arabinoside (B), quercetin 3-rhamnoside (C), quercetin 3-glucoside (D), quercetin 3-rutinoside (E), and quercetin 3-xyloside (F) in the skin of 'Pink Lady' apple during development and ripening in 2002 to 2003 and 2003 to 2004 (three replications). LSD $(P \leq 0.05)$ for 2002 to 2003: quercetin 3-galactoside, 363.7; quercetin 3-arabinoside, 367.2; quercetin 3-rhamnoside, 145.0; quercetin 3-glucoside, 73.4; quercetin 3-rutinoside, 136.5; quercetin 3-xyloside, 1.9. LSD $(P \leq 0.05)$ for 2003 to 2004: quercetin 3-galactoside, 330.5; quercetin 3-arabinoside, 170.8; quercetin 3-rhamnoside, 117.4; quercetin 3-glucoside, 57.8; quercetin 3-rutinoside, 100.4; and quercetin 3-xyloside, 1.9. Vertical bars represent SE. DAFB (d after full bloom). 
(Table 1). Endogenous ethylene was negatively correlated with phloridzin in both seasons. There were no correlations between endogenous ethylene and catechin and epicatechin in both seasons. A significant $(P \leq 0.05)$ positive correlation between ethylene and quercetin 3-galactoside was recorded in 2002 to 2003, but not in 2003 to 2004. Significant negative correlations $(P \leq 0.001)$ were observed between ethylene and quercetin 3 -glucoside and quercetin 3-rutinoside in 2002 to 2003, but not in 2003 to 2004 (Table 1). Therefore increased ethylene concentration during maturation does not appear to regulate the accumulation of quercetin glycosides, because correlations between endogenous ethylene and individual quercetin glycosides were either low or nonsignificant (Table 1).

Recently, Honda et al. (2002) suggested that anthocyanin accumulation in apple skin was the result of the coordinated expression of five genes of the flavonoid pathway during fruit development. However, the levels of expression of these genes and the accumulation of other flavonoids and phenolic compounds such as flavanols, phloridzin, chlorogenic acid, and quercetin glycosides in apples are yet to be investigated.

In conclusion, endogenous ethylene appears to be one of the important factors regulating the development of red color and accumulation of anthocyanin in 'Pink Lady' apple. The accumulation of flavanols (catechin and epicatechin) and quercetin glycosides appears to be independent of ethylene. This study shows that delaying commercial harvest could potentially overcome the problems of poor color development in 'Pink Lady' apple. The implications of date of harvest and delayed harvesting on color development and long-term lowtemperature storage need to be investigated.

\section{Literature cited}

Awad, M.A. and A. de Jager. 2000. Flavonoid and chlorogenic acid concentrations in skin of 'Jonagold' and 'Elstar' apples during and after regular and ultra low oxygen storage. Postharvest Biol. Technol. 20:15-24.

Awad, M.A., A. de Jager, L.H.W. van der Plas, and A.R. van der Krol. 2001. Flavonoid and chlorogenic acid changes in skin of 'Elstar' and 'Jonagold' apples during development and ripening. Sci. Hort. 90:69-83.

Beyer, E.M. and P.W. Morgan. 1970. A method for determining the concentration of ethylene in the gas phase of vegetative plant tissues. Plant Physiol. 46:352-354.

Bishop, R.C. and R.M. Klein. 1975. Photo-promotion of anthocyanin synthesis in harvested apples. HortScience 10:126-127.

Blankenship, S.M. and C.R. Unrath. 1988. PAL and ethylene content during maturation of 'Red' and 'Golden Delicious' apples. Phytochemistry 27:1001-1003.

Bufler, G. 1986. Ethylene-promoted conversion of 1-aminocyclopropane-1-carboxylic acid to ethylene in peel of apples at various stages of development. Plant Physiol. 80:539-543.

Burg, S.P. and E.A. Burg. 1962. Role of ethylene in fruit ripening. Plant Physiol. 37:179-189.

Department of Agriculture Western Australia. 2000. Pink Lady. Minimum International Quality Specifications at Destination, Department of Agriculture Western Australia, Perth, Australia (poster).

Faragher, J.D. and R.L. Brohier. 1984. Anthocyanin accumulation in apple skin during ripening: Regulation by ethylene and phenylalanine ammonia-lyase. Sci. Hort. 22:89-96.

Holden, M. 1965. Chlorophylls, p. 461-488. In: T.W. Goodwin (ed.). Chemistry and biochemistry of plant pigments. Academic Press, London.

Honda, C., N. Kotoda, M. Wada, S. Kondo, S. Kobayashi, J. Soejima, Z. Zhang, T. Tsuda, and T. Moriguchi. 2002. Anthocyanin bio- synthetic genes are coordinately expressed during red coloration in apple skin. Plant Physiol. Biochem. 40:955-962.

Hunter, R.S. 1975. The measurement of appearance. Wiley, New York.

Knee, M. 1972. Anthocyanin, carotenoid and chlorophyll changes in the peel of 'Cox's Orange Pippin' apples during ripening on and off the tree. J. Expt. Bot. 23:184-196.

Kondo, S., J. Uthaibutra, and H. Gemma. 1991. Comparison of 1-aminocyclopropane-1-carboxylic acid, abscisic acid and anthocyanin content of some apple cultivars during fruit growth and maturation. J. Jpn. Soc. Hort. Sci. 60:505-511.

Lancaster, J.E. 1992. Regulation of skin color in apples. Crit. Rev. Plant Sci. 10:487-502.

Lancaster, J.E., C.E. Lister, P.F. Reay, and C.M. Triggs. 1997. Influence of pigment composition on skin color in a wide range of fruit and vegetables. J. Amer. Soc. Hort. Sci. 122:594-598.

Li, Z., S. Sugaya, H. Gemma, and S. Iwahori. 2002. Flavonoid biosynthesis and accumulation and related enzyme activities in the skin of 'Fuji' and 'Oorin' apples during their development. J. Jpn. Soc. Hort. Sci. 71:317-321.

Little, C.R. and R.J. Holmes. 2000. Storage technology for apples and pears. Institute for Horticultural Development, Agriculture Victoria, Knoxfield, Victoria, Australia.

Mackay, A.G., G. Godley, J.E.L. Cripps, E. Melvin-Carter, J. Paterson, and P. Wood. 1994. Pink Lady and Sundowner apples. Bul. no. 4285. Department of Agriculture Western Australia, Perth, Australia.

Mayr, U., D. Treutter, C. Santos-Buelga, H. Bauer, and W. Feucht. 1995. Developmental changes in the phenol concentrations of 'Golden Delicious' apple fruits and leaves. Phytochemistry 38:1151-1155.

McGuire, R.G. 1992. Reporting of objective color measurements. HortScience 27:1254-1255.

Murphey, A.S. and D.R. Dilley. 1988. Anthocyanin biosynthesis and maturity of 'McIntosh' apples as influenced by ethylene-releasing compounds. J. Amer. Soc. Hort. Sci. 113:718-723.

Napolitano, A., A. Cascone, G. Graziani, R. Ferracane, L. Scalfi, C. Di Vaio, A. Ritieni, and V. Fogliano. 2004. Influence of variety and storage on the polyphenol composition of apple flesh. J. Agr. Food Chem. 52:6526-6531.

Rice-Evans, A.C., N.J. Miller, and G. Paganga. 1997. Antioxidant properties of phenolic compounds. Trends Plant Sci. 2: $152-159$

Saltveit, M.E., Jr. 1982. Procedures for extracting and analyzing internal gas samples from plant tissues by gas chromatography. HortScience 17:878-881.

Saure, M.C. 1990. External control of anthocyanin formation in apple. Sci. Hort. 42:181-218.

Siegelman, H.W. and S.B. Hendricks. 1958. Photocontrol of anthocyanin synthesis in apple skin. Plant Physiol. 33:185-190.

Solovchenko, A.E., O.B. Chivkunova, M.N. Merzlyak, and V.A. Gudkovsky. 2005. Relationships between chlorophyll and carotenoid pigments during on- and off-tree ripening of apple fruit as revealed non-destructively with reflectance spectroscopy. Postharvest Biol. Technol. 38:9-17.

Tsao, R., R. Yang, C.J. Young, and H. Zhu. 2003. Polyphenolic profiles in eight apple cultivars using high-performance liquid chromatography (HPLC). J. Agr. Food Chem. 51:63476353.

Walsh, C.S. and T. Solomos. 1987. Ethylene evolution by apple fruits during their early-season growth and development. Sci. Hort. 32:203-211.

Warrington, I.J., T.A. Faulton, E.A. Halligan, and H.N. de Silva. 1999. Apple fruit growth and maturity are affected by early season temperatures. J. Amer. Soc. Hort. Sci. 124:468-477.

Yamauchi, N., Y. Akiyama, S. Kako, and F. Hashinaga. 1997. Chlorophyll degradation in 'Wase satsuma' mandarin (Citrus unshiu Marc.) fruit with on-tree maturation and ethylene treatment. Sci. Hort. 71:35-42. 